\title{
INCIPIENT CONDITION OF SEDIMENT MOTION IN GREAT DIMENSIONLESS FLOW DEPTH
}

\author{
WANG, R. - YU, G. L.* \\ SKLOE, CISSE, School of Naval Architecture, Ocean \& Civil Engineering, Shanghai Jiao Tong \\ University, Shanghai 200240, China \\ (phone: +86-186-1621-6478) \\ *Corresponding author \\ e-mail: yugl@sjtu.edu.cn; phone: +86-134-8215-0851 \\ (Received 28 $8^{\text {th }}$ Mar 2019; accepted 22 $2^{\text {nd }}$ May 2019)
}

\begin{abstract}
The incipient condition of granular sediments in great dimensionless flow depth was studied. A series of experimental runs were performed with four kinds of sediments in a $28 \mathrm{~m}$ long, $6 \mathrm{~m}$ wide flume and the data concerning incipient velocity, water depth and sediment particle size were collected to determine the relationship between incipient velocity and dimensionless water depth. The similarity condition between experimental flow and prototype flow with great dimensionless water depth was analysed according to the logarithmic velocity distribution law in the open channel firstly. The analysis results indicate that water depth cannot be used as a directing-variable for the incipient velocity of granular sediments in great dimensionless flow depth. In order to solve this problem, boundary layer momentum thickness was introduced into flume experiment to replace water depth as the directingvariable. Furthermore, an empirical formula for the incipient velocity of granular sediment in great dimensionless flow depth that includes the proportion of fluid $\gamma$, the proportion of granular sediment $\gamma_{\mathrm{s}}$, the acceleration of gravity $g$ and the dimensionless water depth $(H / d)$ was proposed and the calculated results are more accurate and reasonable compared to previous studies, especially when the dimensionless water depth is greater than $10^{4}$.
\end{abstract}

Keywords: incipient velocity, granular sediment, the ratio of water depth to particle size (H/d), similarity condition, boundary layer momentum thickness

\section{Introduction}

Almost all sediment-related problems in water, including water quality and pollution, scouring, deposition, and issues related to construction and management of reservoirs and canals, and wetland restoration, are associated with the incipient condition of sediment motion (Venditti et al., 2006). In a lake, the bottom currents due to external forces (e.g., winds) can suspend the bottom sediments, thus enhancing the release of contaminants and nutrients from the bed into the water column (Zhang et al., 2018; Zhang and $\mathrm{Yu}, 2017)$. The incipient velocity of sediment is an important parameter to estimate sediment motion as well as riverbed evolution, and to solve the engineering problems of riverbed deformation, bank protection engineering, channel stability and other engineering problems (Zou et al., 2017; Mao et al., 2011). The study on the incipient condition of sediment motion has also great significance to the protection of marine ecological environment, hence it has been a hot topic for decades.

There are two major parameters to describe the incipient condition of sediment motion, i.e., threshold bed shear stress (Rijn, 1984; Chien and Wan, 1999; Yu and Lim, 2003; Zhang and Yu, 2017) and incipient velocity (Beheshti et al., 2008; Francisco et al., 2014). Incipient velocity is more widely used in practices, because only when the flow velocity is sufficiently great, the sedimentary particles which belong to a flat-bed can be dislodged and start to move (Righetti and Lucarelli, 2007; Luo, 2011). In 
addition, the incipient velocity of sediment is the basic of mechanics of sediment motion and riverbed evolution, and is also an important parameter to solve the sediment problems of riverbed deformation, bank protection engineering, channel stability and other engineering problems (Zou et al., 2017; Mao et al., 2011).

There are a lot of efforts on investigating the incipient condition of sediment motion and many useful formulae have been proposed and successfully applied in practical engineering. As early as 1935, according to the experimental data, Hjulstrom found that when the sediment particle size was $0.2-0.3 \mathrm{~mm}$, the incipient velocity of sediment had a minimum value (Phillips, 1992) and since then, scholars from all over the world carried out many experimental research and theoretical analysis, and derived many formulae for the incipient velocity of sediment from the perspective of mechanics and random process. Xie (1981) recommended several representative former Russia formulae such as Shyamov formula (Eq. I), which can be used to calculate the incipient velocity of the granular sediments with the particle size $d>0.15 \mathrm{~mm}$ and Goncharov formula (Eq. 2).

$$
\begin{gathered}
v_{c}=1.14 \sqrt{\frac{\rho_{s}-\rho}{\rho} g d}\left(\frac{h}{d}\right)^{\frac{1}{6}} \\
v_{c}=1.07 \sqrt{\frac{\rho_{s}-\rho}{\rho} g d} \lg \left(\frac{h}{d}\right)^{\frac{1}{6}}
\end{gathered}
$$

where $d=$ the particle size, $v_{c}=$ the incipient velocity of sediments, $h=$ the depth of water, $\rho$ and $\rho_{s}$ were the density of fluid and sediment particle respectively, $g=$ acceleration of gravity, $\xi$ and $m$ were the undetermined coefficients. Considering the viscosity of fine sediment, many Chinese scholars have proposed new formulae for the incipient velocity of sediment. Dou (1960) proposed a formula for the incipient velocity of sediment in shallow water in 1960 and modified it in 1974, such as Equation 3.

$$
v_{c}=0.32\left(\ln 11 \frac{h}{k_{s}}\right)\left[\left(\frac{\rho_{s}-\rho}{\rho}\right) g d+0.19\left(\frac{\varepsilon_{k}+d h \delta}{d}\right)\right]^{0.5}
$$

where $\delta=0.213 \times 10^{4} \mathrm{~cm} ; \varepsilon_{k}=2.56 \mathrm{~cm}^{2} / \mathrm{s}^{2}, k_{s}$ is riverbed roughness, and for the flat bed, $k_{s}=0.5 \mathrm{~mm}$ when $d \leq 0.5 \mathrm{~mm}$ and $k_{s}=d$ when $d>0.5 \mathrm{~mm}$. Zhang (1961) proposed Equation 4, which is the formula of Wuhan Institute of Hydraulic and Electric Engineering and adopted in Chinese code.

$$
v_{c}=\left[1.76\left(\frac{\rho_{s}-\rho}{\rho}\right) d+0.000000605\left(\frac{10+h}{d^{0.72}}\right)^{0.5}\left(\frac{h}{d}\right)^{0.14}\right.
$$

However, the parameters introduced by previous research results which are mostly determined by the flume experiments would affect the accuracy of the formulae, because the water depth in flume is always limited to $0.1-0.5 \mathrm{~m}$, whereas the actual estuary water depth can reach 5-10 m, sometimes even about $20 \mathrm{~m}$ (Zeng et al., 2010). Compared with other formulas, the formula (Eq. 5) of Sha (1965) payed more attention 
to the influence of increased water depth on the incipient velocity of sediment, which was closer to the natural river (Zhang, 2012).

$$
v_{c}=\sqrt{\frac{\rho_{\mathrm{s}}-\rho}{\rho} g d h^{1 / 5}}\left[266\left(\frac{\delta}{d}\right)^{1 / 4}+0.66 \times 10^{9}(0.7-\varepsilon)^{4}\left(\frac{\delta}{d}\right)^{2}\right]^{1 / 2}
$$

where $\delta=$ the film water thickness and $\delta=0.0001 \mathrm{~mm} ; \varepsilon$ was the porosity and $\varepsilon \cong 0.4$ ). Whereas, Han et al. (1982) considered that the formula of Sha (1965) took the influence of the bonding force caused by contact between sediment particles and the porosity on the incipient velocity of sediment into account, but the mechanical mechanism was not described and expressed clearly. Therefore, the formula for the incipient velocity of sediment needs to be further studied.

The formulae of the incipient velocity of sediment are based on limited water depth which may result in their inapplicability (Zeng et al., 2010). The formula form $v_{c}=k d^{1 / a} h^{1 / 6}$ is almost adopted to calculate the incipient velocity of non-viscous sediment (Karmer, 1935; He et al., 2002). Nie et al. (2004) summarized dozes of the existing formulas and derived the unified formula $(E q .6)$, whereas the values of $\xi$ and $m$ were slightly different in different formulae.

$$
v_{c}=\xi \sqrt{\frac{\rho_{s}-\rho}{\rho} g d\left(\frac{h}{d}\right)^{m}}
$$

In most cases, the value of $m$ is $1 / 6$ and the of value $\xi$ is usually between 3.37 and 7 (Nie, 2004). He et al. (2002) believed that $\xi$ was not a constant, but within a certain range and changed with the relative exposure of particles on the bed surface. However, it is found that the value of $\xi$ at different flow levels is variable according to the analysis of the 246 groups of data on sediment initial motion at Yichang station which is one of the reservoirs of Three Gorges in China (Li et al., 2006). Li et al. (2006) used the normative formula of Wuhan Institute of Hydraulic and Electric Engineering and Shyamov formulae to calculate the incipient velocities of sediment based on the different flow levels at the Yichang station, and there was a huge error between the calculated results and the field measured data, especially in the case of huge flow. In addition, the coefficient $\xi$ of Equation 6 varies greatly when it is used to calculate the incipient velocities of the granular sediments with different particle sizes in the flow with the same water depth, i.e., Lu (1991) proposed the formulae for the incipient velocity of the pebble in the Yangtze river (its $H / d$ range is $80 \sim 1000$ ) and sandy and muddy (the range $H / d$ of was $10000 \sim 100000$ ), which based on the field measured data of sediment initial motion in the Yangtze river, but the value of $\xi$ are 0.95 and 1.47, respectively, between which the difference is 1.55 times. Therefore, it is still necessary to study the incipient velocity of sediment under the premise of fully considering the influence of water depth or relative water depth on the incipient velocity of sediment.

To ensure that the formulae for the incipient velocity of sediment obtained by the flume experiments are more accurate and reliable, the similarity conditions between the experimental flow and the prototype flow with great dimensionless water depth should be satisfied (Ferro, 1999; Falcão et al., 2014; Dornbrack and Schumann, 1993; Steward and Tennankore, 1977). According to the force analysis of the sediment particles on the horizontal bed without seepage, only the drag force and the lifting force are favorable to 
the initial motion of sediment particles, except the geometric status of sediment particles and the bed roughness (Niven, 2010; Bohorquez and Fernandez-Feria, 2008; Mao et al., 2011). Therefore, the distribution of the flow velocity on vertical line in the experimental flow and the prototype flow with great dimensionless water depth should satisfy the principle of similitude to ensure the accuracy of the experimental results, because the distribution of flow velocity would be affected by different water depth, which would have an impact on the Kinematic similarity between the experiment flow and the prototype flow with great dimensionless water depth. The velocity distribution in experimental flow and natural open channel flow generally adopt the logarithmic formula of velocity distribution (Yu and Tan, 2006; Meftah and Mossa, 2016) and the formula can be written as

$$
\frac{u}{u_{*}}=\frac{1}{k} \ln \left(\frac{y}{\Delta}\right)
$$

where $y=$ the height from the bed, $u=$ the velocity at the height $y, u *=$ the friction velocity, $\kappa=$ the Carmen coefficient, $\Delta=$ the rigidity of bed sediment and $\Delta=K_{s} / 30.2$ (Nikuradse, 1933), $K_{s}$ is the characteristic particle size of the bed surface. Hence, the similarity conditions between the experimental flow and the prototype flow with great dimensionless water depth would be analyzed firstly according to the logarithmic velocity distribution law in open channel.

In this study, a series of experimental runs were conducted and the previous data were collected. Finally, a new formula for the incipient condition of the granular sediment in great dimensionless water depth was proposed. Section 2 described the analysis of Similarity condition between experimental flow and prototype flow with great dimensionless water depth. Section 3 described the derivation and the structure of the empirical formula for the incipient velocity of granular sediment in the flow with great dimensionless water depth. Section 4 described the test materials, experimental setup, and test procedure. In section 5, the experimental results were presented, and the parameters of the empirical formula were determined. In addition, the soundness and the accuracy of this empirical formula were verified by comparing with previous studies. Finally, section 6 presented the main conclusions of the study and the recommendations for future studies.

\section{Theoretical basis}

\section{Similarity requirement for sediment motion in different flow depths}

In this paper, the similarity condition between the experimental flow and the prototype flow with great dimensionless water depth was analysed based on the logarithmic velocity distribution law in open channel. It is assumed that the experimental flow was to be able to fully simulate the prototype flow with great dimensionless water depth. Some assumptions are made to better illustrate the similarity between the experimental flow and the prototype flow. The flow distributions in an experimental flume and in a prototype flow are shown in Figure 1, where the subscript $m$ denotes model (experimental flume) and the subscript $p$ denotes the prototype. $H_{p}$ and $H_{m}$ is the flow depth in the experimental flume and in the prototype flow, respectively. Suppose $H_{p} / H m=\lambda$. The velocity in the experimental flow at the height $y_{m 1}$ and $y_{m 2}$ 
from the bed surface are assumed as $u_{m 1}$ and $u_{m 2}$, and the corresponding velocities in the prototype flow with great dimensionless water depth at the height $y_{p 1}=\lambda y_{m 1}$ and $y_{p 2}=\lambda y_{m 2}$ from the bed surface are assumed as $u_{p 1}$ and $u_{p 2}$. The particle sizes of the experiment flume bed and corresponding prototype bed are assumed as $d_{m}$ and $d_{p}$, respectively.

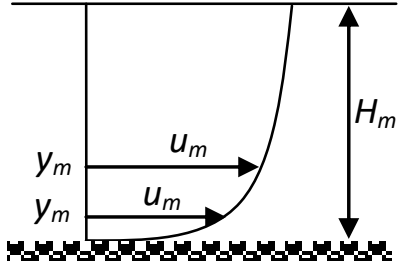

(a) Experimental flow

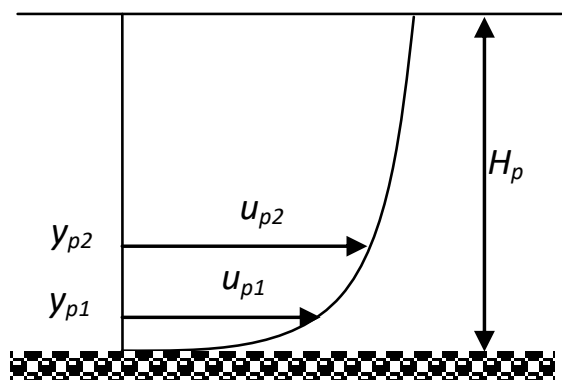

(b) Prototype flow

Figure 1. Vertical velocity distribution

Suppose $K_{s}=d$ (Bennett and Best, 1995; Mianaei et al., 2010) for the uniform sediment. Hence,

$$
\begin{aligned}
& \frac{u_{m 1}}{u_{*_{m}}}=\frac{1}{\kappa} \ln \left(30.2 \frac{y_{m 1}}{d_{m}}\right) \\
& \frac{u_{m 2}}{u_{* m}}=\frac{1}{\kappa} \ln \left(30.2 \frac{y_{m 2}}{d_{m}}\right) \\
& \frac{u_{p 1}}{u_{* m}}=\frac{1}{\kappa} \ln \left(30.2 \frac{y_{p 1}}{d_{m}}\right) \\
& \frac{u_{p 2}}{u_{* m}}=\frac{1}{\kappa} \ln \left(30.2 \frac{y_{p 2}}{d_{m}}\right)
\end{aligned}
$$

Equation 8 is divided by Equation 9, and the parameters $u *_{m}$ can be eliminated. In a similar way, Equation 11 is divided by Equation 10, and the parameters $u *^{*}$ can be also eliminated. Hence,

$$
\frac{u_{m 1}}{u_{m 2}}-\frac{u_{p 1}}{u_{p 2}}=\frac{\ln \left(30.2 \frac{y_{m 1}}{d_{m}}\right)}{\ln \left(30.2 \frac{y_{m 2}}{d_{m}}\right)}-\frac{\ln \left(30.2 \frac{y_{p 1}}{d_{p}}\right)}{\ln \left(30.2 \frac{y_{p 2}}{d_{p}}\right)}
$$

Equation 12 can be further simplified, and the similarity condition between the experimental flow and the prototype flow with great dimensionless water depth can be written as 


$$
\frac{u_{m 1}}{u_{m 2}}-\frac{u_{p 1}}{u_{p 2}}=\frac{\ln \left(\frac{y_{m 2}}{y_{m 1}}\right)\left[\ln \left(\frac{d_{p}}{d_{m}}\right)-\ln (\lambda)\right]}{\ln \left(30.2 \frac{y_{m 2}}{d_{m}}\right) \ln \left(30.2 \frac{y_{p 2}}{d_{p}}\right)}
$$

According to kinematic similarity criteria, it can be seen from Equation 13, when $\lambda=d_{p} / d_{m}, u_{m 1} / u_{m 2}$ is equal to $u_{p 1} / u_{p 2}$. In other words, only when the dimensionless water depth (the ratio of water depth to particle size, $H_{m} / d_{m}$ ) in experimental flow is the same as that in corresponding prototype flow $H_{p} / d_{p}$, the flow velocity near the particles in experimental flow is similar with that in corresponding prototype flow and the motion of the sediment is similar in both scenarios. Otherwise, if $\lambda<d_{p} / d_{m}$, $u_{m 1} / u_{m 2}$ is larger than $u_{p 1} / u_{p 2}$ which indicates that the flow velocity near the sediment particles in experimental flow is higher than that in corresponding prototype flow, and the sediment particles in experimental flow would be easier to be dislodged than that in corresponding prototype flow. On the other hand, when $\lambda>d_{p} / d_{m}, u_{m 1} / u_{m 2}$ is smaller than $u_{p 1} / u_{p 2}$, which indicates that the flow velocity near the sediment particles in experimental flow would be lower than that in corresponding prototype flow, and the sediment particles in experimental flow are then more difficult to be dislodged than that in corresponding prototype flow. It is seen that similarity condition between experimental flow and corresponding prototype flow is that the sediment particle size scale $\left(d_{p} / d_{m}\right)$ equal to water depth scale $\left(H_{p} / H_{m}\right)$, that is, $H_{p} / d_{p}=H_{m} / d_{m}$. Hence, the similarity between experimental flow and corresponding prototype flow is necessary to ensure the similar flow velocity near the sediment particles near bed in experimental flow and corresponding prototype flow.

In line with the similarity analysis between the experimental flow and the prototype flow in great dimensionless water depth, the current formulae deduced from flume experiments may be not suitable for calculating the incipient velocity of the granular sediment motion in great dimensionless depth of water, which requires a wide range of $H / d$ in the flume experiment, for example, the water depth varies from 10 to $40 \mathrm{~m}$, and the sediment particle sizes are between 0.2 and $2 \mathrm{~mm}$ in the middle reaches of the Yangtze river ( $\mathrm{Lu}, 1991$ ), thus the range of $H / d$ is more than 200,000, and, the $H / d$ range from 2 to 2030 according to the 272 groups of experimental data collected by author. On the other hand, non-natural sediments such as the homogeneous model sediments are always used in flume experiments (Geiger and Durnford, 2000; Thomas and Calantoni, 2001; Jain and Juans, 2009), and the particle size of the homogeneous model sediment is relatively larger than that of the natural sediments, which cannot be used to simulate the motion of cohesive sediments. Because the particle size of the cohesive sediments is always less than $0.06 \mathrm{~mm}$ (Grabowski et al., 2011; Jean Berlamont et al., 1993), and the viscosity between cohesive sediment particles will affect the incipient condition of sediments (Mehta, 1984 and1989; Lumborg and Windelin, 2003). Therefore, the limitation of experimental flume size would affect the accuracy of the existing formulas for the incipient velocity for the granular sediments in the flow with great dimensionless water depth, and and the water depth in flume experiment should not be used as the direct variable of the formulas for the incipient condition of the sediment in the flow with great dimensionless water depth. 


\section{Boundary layer momentum thickness calculation}

In this paper, boundary layer momentum thickness was introduced into the flume experiment as the independent variable to calculate the incipient velocity of the granular sediment in the flow with great dimensionless water depth. Boundary layer thickness reflects the block effect of bed wall and Roux (2010) regarded that the incipient motion of sediment is mainly affected by the flow near bed, that is, the flow near the boundary layer and the influence of the flow velocity outside the boundary layer on the sediment motion could be ignored in deep water area. Due to the viscous effect of fluid, the change of flow velocity in boundary layer will cause the loss of momentum in the boundary layer. The loss of momentum in the boundary layer can be explained by the momentum thickness of the boundary layer. Therefore, the boundary layer momentum thickness can be taken as a direct factor affecting sediment motion, which should be used to calculate the incipient velocity of sediment, rather than the water depth.

In general, boundary layer momentum thickness $\delta^{1}$ is used to describe the boundary layer thickness intuitively (Hokenson, 1977), which can be written as follows:

$$
\rho \delta^{1} U^{2}=\int_{0}^{\delta^{*}} \rho u(U-u) d y
$$

where $\rho$ is the density of water, $\mathrm{kg} / \mathrm{m}^{3} ; \delta^{1}$ is boundary layer momentum thickness; $\delta^{*}$ is the boundary layer thickness, $m$. $U$ and $u$ are supposed to comply with the logarithmic velocity distribution law (Jonsson, 1966). Therefore, Equation 14 can be written as

$$
\rho \delta^{1}=\frac{\delta^{*}}{\ln \left(30.2 \frac{\delta^{*}}{d}\right)}-\delta^{*}-\frac{1}{\left[\ln \left(30.2 \frac{\delta^{*}}{d}\right)\right]^{2}} \int_{0}^{\delta^{*}} \ln ^{2}\left(30.2 \frac{y}{d}\right) d y
$$

where $y$ is the water depth where the velocity is $u, m / s$. It is assumed that

$$
x=30.2 \frac{y}{d}
$$

So Equation 15 can be derived as Equation 17.

$$
\delta^{1}=\frac{\delta^{*}}{\ln \left(30.2 \frac{\delta^{*}}{d}\right)}+2 \frac{\delta^{*}}{\ln ^{2}\left(30.2 \frac{\delta^{*}}{d}\right)}
$$

In the flume scale, the boundary layer thickness is determined by the water depth of the flume, that is $\delta^{*}=H$, and the boundary layer momentum thickness in shallow water area such as in the flume can be calculated by Equation 18.

$$
\delta^{1}=\frac{H}{\ln \left(30.2 \frac{H}{d}\right)}+2 \frac{H}{\ln ^{2}\left(30.2 \frac{H}{d}\right)}
$$




\section{Formula form derivation}

In this section the formula form for the incipient velocity of the granular sediment in the flow with great dimensionless water depth was analysed. The incipient motion of sediment is mainly affected by incipient condition which should conclude the characteristics of sediment particles, flow conditions and the relationship between flow conditions and sediment particles (Wang et al., 2008). Hence, the incipient velocity of granular sediment is influenced by the proportion of sediment particle, the proportion of fluid, kinematic viscosity coefficient, salinity, acceleration of gravity besides boundary layer momentum thickness. While the kinematic viscosity coefficient and saltiness can be ignored, because the temperature has little impact on the kinematic viscosity coefficient of fresh water and sea water (Balucani et al., 1996). Therefore, the formula form of the incipient velocity for the granular sediment particle can be written as

$$
v_{c}=f\left(g, \gamma, \gamma_{s}, d, \delta^{1}\right)
$$

where $\gamma$ is the proportion of water, $\mathrm{kg} / \mathrm{m}^{3} ; \gamma_{s}$ is the proportion of sediment, $\mathrm{kg} / \mathrm{m}^{3}$. As mentioned above, Equation 6 is almost adopted as the formula form to calculate the incipient velocity of sediment, therefore the formula form of the granular sediment in the flow with great dimensionless water depth can be expressed as:

$$
v_{c}=\xi\left(\frac{\gamma_{s}-\gamma}{\gamma} g d\right)^{a} d^{b} \delta^{1^{c}}
$$

where $\xi, a, b, c$ are constants. In this paper, $d=D_{50}$. It can be deduced that $a=0.5$, $b=c$ by the dimensional analysis of Equation 20. Therefore, the formulary structure of incipient velocity for the granular sediment particle can be written as

$$
v_{c}=\xi\left(\frac{\gamma_{s}-\gamma}{\gamma} g d\right)^{a} d^{0.5}\left(\frac{\delta^{1}}{d}\right)^{c}
$$

Compared with Equation 6, water depth $H$ is replaced by the boundary layer momentum thickness $\delta^{1}$ in Equation 21, which is confirmed to the similarity requirement between the experimental flow and the prototype flow with great dimensionless water depth for sediment initial motion.

\section{Materials and method}

\section{Test materials}

Four kinds of sediment particles with different particle sizes were used for the tests, which concluded one kinds of model sediments (MS) and three kinds of natural sediments. The homogeneous granular plastic sands were used as the test sediments which can be applied to the model experiment with different scale. The particle size of the homogeneous granular plastic sands in this experiment was $3.2 \mathrm{~mm}$ and the proportion of the homogeneous granular plastic sands was $1050 \mathrm{~kg} / \mathrm{m}^{3}$. The natural sediments were from different places: coastal line of Fengxian (FX), Shanghai, China; Huangpu River (HPJ) of Shanghai; coastal line of Zhuhai (ZH), Guangzhou province. 
The natural sediments were dried for $24 \mathrm{~h}$ in an oven at a temperature of $105^{\circ}$. After that, the dried sediments were sieved through a series of standard sieves with different diameters of holes to screen suitable sediment particle sizes and eliminate impurities such as small stones and shellfish. The determination range of standard sieves in laboratory is $0.038 \sim 6 \mathrm{~mm}$. All the grain size and grain density are summarized in Table 1 .

Table 1. Grain size and grain density

\begin{tabular}{c|c|c|c}
\hline Location of sediment & FX & HPJ & ZH \\
\hline Grain density $\left(\mathrm{g} / \mathrm{cm}^{3}\right)$ & 2.02 & 2.23 & 1.98 \\
Median particle size $(\mathrm{mm})$ & 0.33 & 0.84 & 1.22 \\
Standard deviation of grain size $(\mu \mathrm{m})$ & 1.6 & 2.6 & 0.9 \\
Sorting coefficient & 1.85 & 2.11 & 1.80 \\
\hline
\end{tabular}

In addition, 272 groups of previous data concerning the incipient velocity of granular sediment, water depth and sediment particle size were collected to verify and fit the formula for the incipient velocity for granular sediments in the flow with great dimensionless water depth. The rang of the sediment proportion of the collected data is from 2010 to $2650 \mathrm{~kg} / \mathrm{m}^{3}$, and the rang of the sediment particle sizes of the collected data are from 0.04 to $22.2 \mathrm{~mm}$. The maximum depth selected from the collected data is $0.47 \mathrm{~m}$.

\section{Experiment setup}

The flume experiment was performed in the laboratory to examine the incipient velocities of the sediments with different particle size. The layout of the experimental apparatus is shown in Figure 2. The experimental flime was a water-circulating rectangle flume with a length of $10 \mathrm{~m}$, width of $1 \mathrm{~m}$, height of $1 \mathrm{~m}$. A rectangular groove with dimensions of $50 \mathrm{~cm}$ length, $1 \mathrm{~m}$ width, and $5 \mathrm{~cm}$ depth was arranged at the bottom of the rectangular flume. The sample box with different sediment particles was placed in a groove during the experiment. The upper surface of the sample box was aligned with the inner wall of the flume to ensure that the inner surface of the flume was flat. Windows are provided on both sides of the flume to facilitate the observation of sediment motion. Two flow straighteners were installed at the upstream and downstream ends of the flume, respectively, to ensure that the water flowed evenly in the test range of the flume. The water inlet and water outlet are on the left side of the flume which can be controlled by the valve. The valves of water inlet and water outlet were closed during the experiment. A pump was arranged under the water-circulating rectangle flume and connected with the flume, flow meter and flow control valve by the pipe. The pump is ISG type vertical pipe centrifugal pump. The lift of this pump is $60 \mathrm{~m}$ and the flow is $45 \mathrm{~m}^{3} / \mathrm{h}$. The flow control valve was used to control the flow in the flume. The flow meter is an electromagnetic flowmeter whose nominal diameter is DN6-DN2000 with wide coverage. The flow velocity in the flume was measured by UDV 3000. 




Figure 2. Experiment setup

\section{Test procedure}

First, tap water was added into the flume through the water inlet on the left side of the flume, and the valve of water outlet was closed at this time. When the water depth reaches a certain level, the valve of water inlet was closed. The depth of the water by artificial control was between 10 and $50 \mathrm{~cm}$. The sample box with the sediment samples inside was then lowered into the square box. Subsequently, the pump was turned on and the flow control valve was then opened slowly. The incipient motion of sediment was observed through the windows on both sides of the flumes. The flow velocity was accelerated very slowly by $1-2 \mathrm{~cm} / \mathrm{s}$ every minute until a few sediment particles were dislodged from the bed surface, and the flow velocity was recorded at this time. The incipient criterion of sediment is that about 1\%o of the particles dislodged from the bed surface (Kramer, 1935; Chien and Wan, 1983), which also applies to model sediment (Huang et al., 2012). This phenomenon that the sediment particles dislodge from the bed surface continuously took place in both time and space, that is, the sediment motion could always be observed throughout the experiment (Zhang et al., 2017). Because the incipient criterion of sediment processed a certain amount of subjectivity and judgment (He et al., 2003; Huang et al., 2012), there must be some divergent data in the experimental results. In order to minimize the errors of inevitable subjectivity associated with incipient criterion of sediment, the procedure for measuring the flow velocity when the phenomenon that a few sediment particles were dislodged from the bed surface was observed was repeated three times for every sediment samples. Once the incipient criterion of sediment samples was reached, the flow velocity, and the difference of water head were recorded.

\section{Results and discussion}

\section{Empirical formula for the incipient velocity for granular sediment in the flow with great dimensionless water depth}

In this section, the coefficients $\xi$ and $c$ of Equation 21 are discussed by means of data fitting and collection. A series of previous data were collected, which include the experimental date of incipient condition of sediment collect by Yang et al. (2006) and a part of the sediment experimental data collected by Brownlie (1981). The basis of the 
data screened from the data collected by Brownlie (1981) is that the suspended sediment concentration range of the collected data should be between 0 PPM and 3 PPM, according to the analysis of sediment transport and the distribution of suspended sediment concentration in the fluid when the sediment particles begin to suspend (Ted et al., 1974) and these screened data included the experiment data of Simons, Bishop and Richardson (1965), Yalin and Karahan (1979), Govt. of West Bengal (1965), Casey (1935), Costello (1974), Davies (1971), Guy at al. (1966), Ho (1939), Mavis et al. (1937), Mutter (1971), Nordin (1976), Oerien (1935), Paintal (1971), Pratt (1970), Taylor (1971). The experimental results are shown in Table 2. The collected data are shown in the Appendix.

Table 2. Experimental results

\begin{tabular}{c|c|c|c|c|c|c|c|c}
\hline \multirow{2}{*}{$\boldsymbol{H}(\boldsymbol{m})$} & \multicolumn{9}{c}{ Location of sediment } \\
\cline { 2 - 9 } & \multicolumn{2}{|c|}{$\mathbf{F X}$} & \multicolumn{2}{c}{ HPJ } & \multicolumn{2}{c}{ ZH } & \multicolumn{3}{c}{ MS } \\
\cline { 2 - 9 } & $\boldsymbol{H} / \boldsymbol{d}$ & $\boldsymbol{V}_{\boldsymbol{c}}(\boldsymbol{m} / \boldsymbol{s})$ & $\boldsymbol{H} / \boldsymbol{d}$ & $\boldsymbol{V}_{\boldsymbol{c}}(\boldsymbol{m} / \boldsymbol{s})$ & $\boldsymbol{H} / \boldsymbol{d}$ & $\boldsymbol{V}_{\boldsymbol{c}}(\boldsymbol{m} / \boldsymbol{s})$ & $\boldsymbol{H} / \boldsymbol{d}$ & $\boldsymbol{V}_{\boldsymbol{c}}(\boldsymbol{m} / \boldsymbol{s})$ \\
\hline 0.131 & 393.94 & 0.1876 & 154.76 & 0.281 & 106.56 & 0.2713 & 40.63 & 0.0888 \\
0.149 & 451.52 & 0.1919 & 177.38 & 0.288 & 122.13 & 0.2775 & 46.56 & 0.0909 \\
0.169 & 512.12 & 0.1959 & 201.19 & 0.294 & 138.52 & 0.2833 & 52.81 & 0.0928 \\
0.206 & 624.24 & 0.2025 & 245.24 & 0.304 & 168.85 & 0.2927 & 64.38 & 0.0958 \\
0.237 & 718.18 & 0.2072 & 282.14 & 0.311 & 194.26 & 0.2996 & 74.06 & 0.0981 \\
0.296 & 895.45 & 0.2150 & 351.79 & 0.322 & 242.21 & 0.3108 & 92.34 & 0.1017 \\
0.333 & 1010.61 & 0.2194 & 397.02 & 0.329 & 273.36 & 0.3171 & 104.22 & 0.1038 \\
0.366 & 1109.09 & 0.2228 & 435.71 & 0.334 & 300 & 0.3219 & 114.38 & 0.1054 \\
0.385 & 1166.67 & 0.2247 & 458.33 & 0.337 & 315.57 & 0.3247 & 120.31 & 0.1063 \\
0.426 & 1290.91 & 0.2285 & 507.14 & 0.343 & 349.18 & 0.3302 & 133.13 & 0.1081 \\
\hline
\end{tabular}

The coefficients of Equation 21 were determined respectively using the test results and the collected data with the help of Origin 9.0 and Excel 2017. Firstly, the formal deformation of Equation 21 was carried out in order to simplify the calculation as follows: the opposite sides of Equation 21 was taken logarithm respectively, and then the multivariate regression method was used to determine these coefficients. These coefficients were evaluated as follows: $\zeta=1.74, \mathrm{c}=0.18$. The value of $\mathrm{R}^{2}=86 \%$ indicates that the fit of the obtained model is fairly-good. Hence, the incipient velocity for the granular sediments in the flow with great dimensionless water depth can be expressed as follows:

$$
v_{c}=1.74\left(\frac{\gamma_{s}-\gamma}{\gamma} g d\right)^{0.5}\left(\frac{H}{d}\right)^{0.18}\left[\frac{1}{\ln \left(30.2 \frac{H}{d}\right)}+\frac{2}{\ln ^{2}\left(30.2 \frac{H}{d}\right)}\right]^{0.18}
$$

As show in Figure 3, the curves plotted using the calculated values based on Equation 22 are in accordance with the experimental data and the collected data, and this formula possesses an acceptable accuracy for calculating $V_{c}$, as $86 \%$ of the datasets are within a confidence interval with a relative error of $20 \%$. 


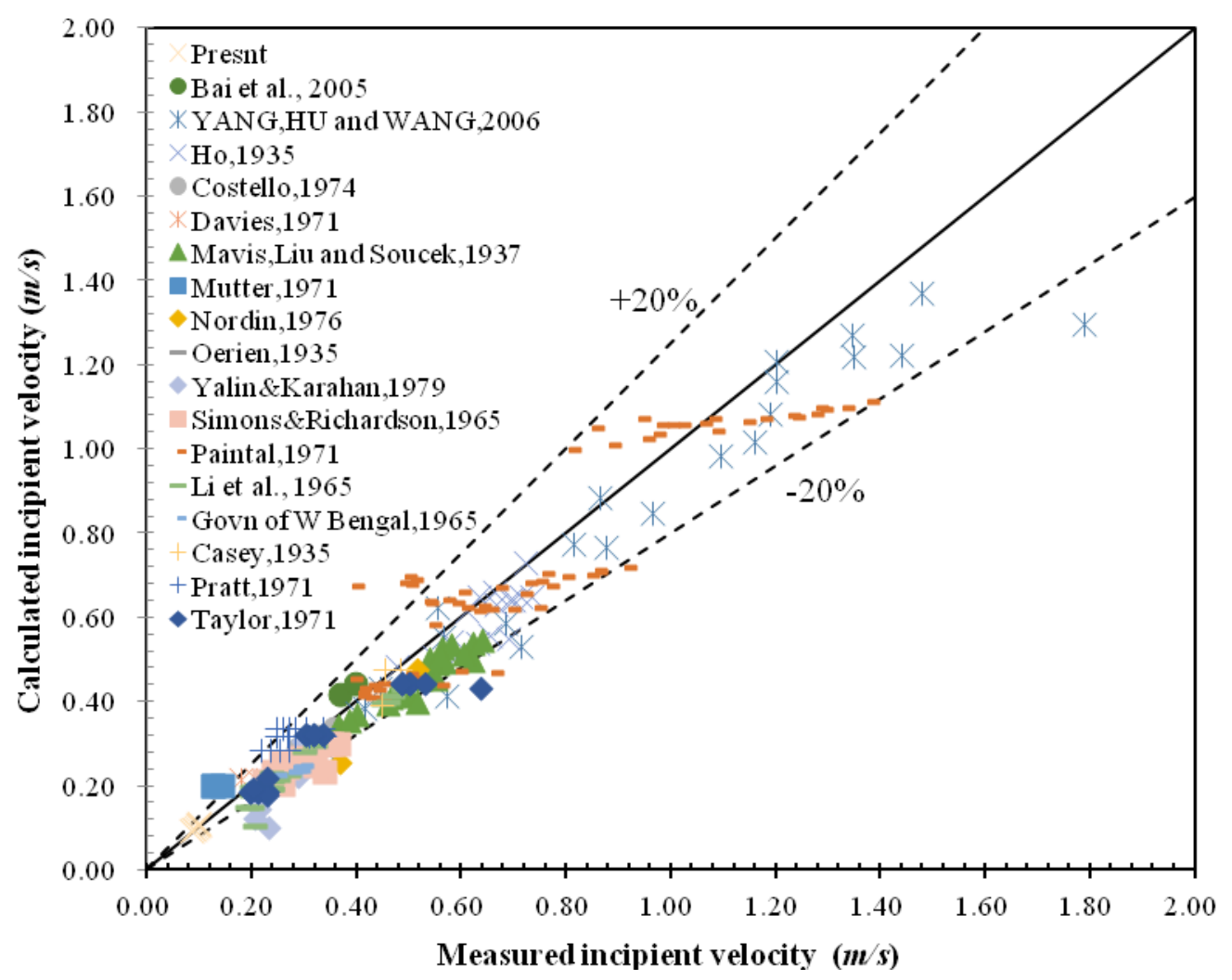

Figure 3. Comparison between the measured and the calculated incipient velocity

The incipient velocity of granular sediments in the flow with great dimensionless water depth are plotted according to Equation 22, and an incipient velocity diagram is drawn, as shown in Figure 4. The incipient velocity of granular sediments in the flow with great dimensionless water depth are plotted as a function of the dimensionless water depth $(H / d)$ with the particle size as an independent parameter. It can be seen from Figure 4 that the incipient velocity of the granular sediments in the flow with great dimensionless water depth increases with the increase of the dimensionless water depth $(H / d)$ and the particle size, i.e., the incipient velocity of the granular sediments in the flow with great dimensionless water depth increases from $0.2 \mathrm{~m} / \mathrm{s}$ to $0.45 \mathrm{~m} / \mathrm{s}$ when the particle size increases from $0.1 \mathrm{~mm}$ to $5 \mathrm{~m} / \mathrm{s}$ and the great dimensionless water depth is 5000; the incipient velocity of the granular sediments in the flow with great dimensionless water depth increases from $0.2 \mathrm{~m} / \mathrm{s}$ to $0.625 \mathrm{~m} / \mathrm{s}$ when the great dimensionless water depth $(H / d)$ increases from 5000 to 4000000 and the particle size is $0.5 \mathrm{~mm}$.

\section{Soundness verification this empirical formula}

The incipient velocity of granular sediments in the flow with great dimensionless water depth calculated by Equation 22 proposed in this paper was compared with that calculated by Equation 4 of Wuhan Institute of Hydraulic and Electric Engineering which has been used as a normative formula for the calculation of incipient velocity of sediment to verify the soundness of Equation 22, Figure 5 depicts the incipient velocities of sediment in the flow with great dimensionless water depth $(H / d)$ with various particle size, which are calculated by Equation 22 and the formula of Wuhan 
Institute of Hydraulic and Electric Engineering. The comparison between calculated results of the empirical Equation 22 and the normative formula of Wuhan Institute of Hydraulic and Electric Engineering clearly indicates the following:

The incipient velocities of the granular sediments calculated by the two formulas both increases with the increase of the dimensionless water depth $(H / d)$ and the particle size of granular sediment.

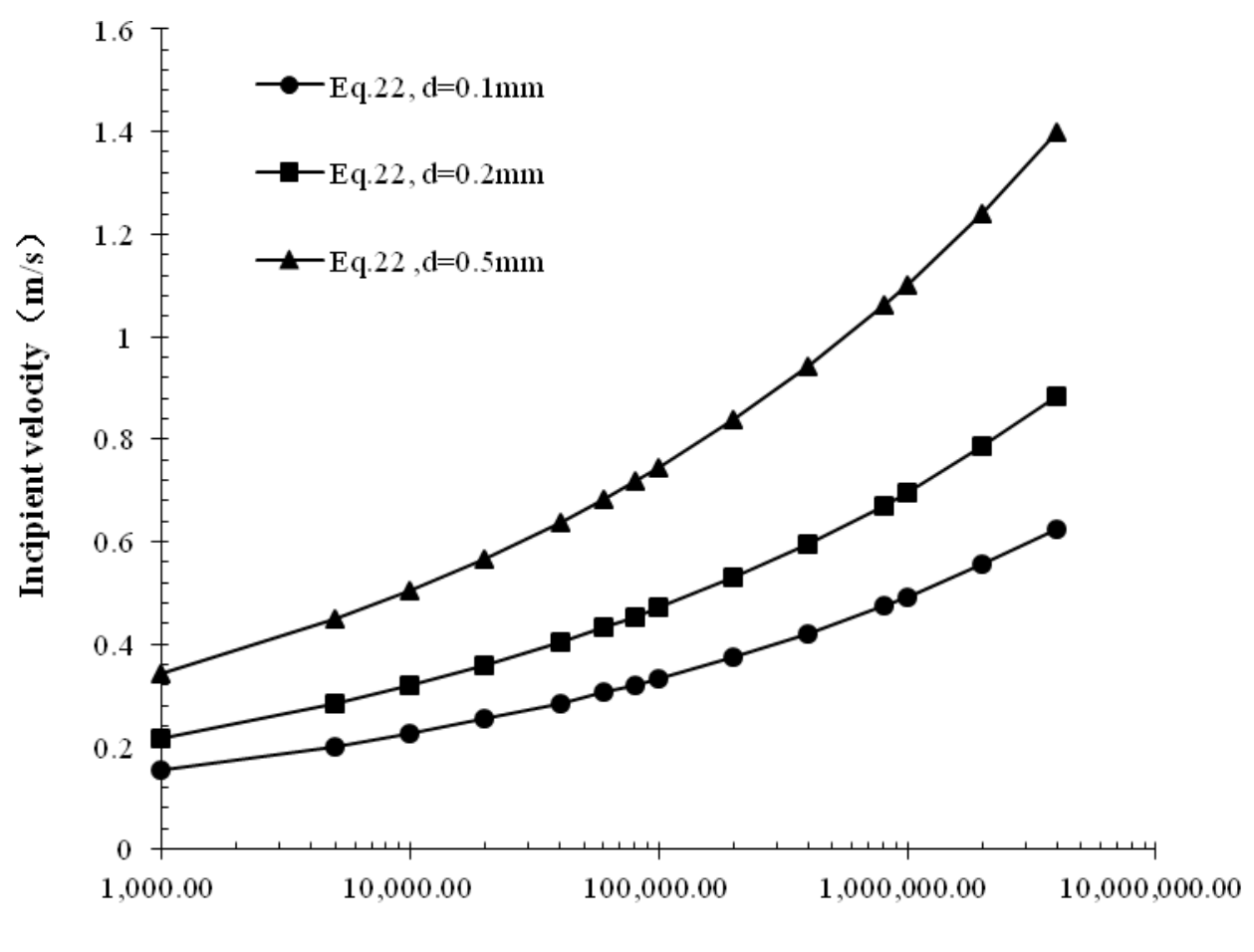

Dimensionless water depth $(H / d)$

Figure 4. Incipient velocity diagram

For $H / d \leq 1 \times 10^{4}$, the increasing trend of the incipient velocities of the granular sediments calculated by Equation 16 with the dimensionless water depth $(H / d)$ is similar with that calculated by the normative formula of Wuhan Institute of Hydraulic and Electric Engineering, and all increase slowly. Whereas, the incipient velocities of the granular sediments calculated by Equation 16 is lower than that calculated by the normative formula of Wuhan Institute of Hydraulic and Electric Engineering when the particle size is less than or equal to $0.2 \mathrm{~mm}$. When the particle size is more than $0.2 \mathrm{~mm}$, the incipient velocities of the granular sediments calculated by Equation 22 is approximately equal that calculated by the normative formula of Wuhan Institute of Hydraulic and Electric Engineering.

For $H / d>1 \times 10^{4}$, the increasing trend of the incipient velocities of the granular sediments calculated by Equation 22 is much slower than that by the normative formula of Wuhan Institute of Hydraulic and Electric Engineering, which demonstrates that there will be a large difference between incipient velocities of granular sediment calculated by Equation 22 and the normative formula of Wuhan Institute of Hydraulic and Electric Engineering when the dimensionless water depth $(H / d)$ is more than $10^{4}$, and the difference increases with the increase of $H / d$. In order to illuminate the 
appearance, Wanxian site is taken as an example, which is one of the reservoirs of Three Gorges in China. The particle size of the sediment at Wanxian site is less than $0.16 \mathrm{~mm}$ and the depth of water will reach $100 \mathrm{~m}$ when the reservoir is full of water (Wang et al., 2010). But the incipient velocities of the sediment at Wanxian site calculated by Equation 22 and the normative formula of Wuhan Institute of Hydraulic and Electric Engineering are $1.306 \mathrm{~m} / \mathrm{s}$ and $0.601 \mathrm{~m} / \mathrm{s}$ respectively, which differ widely.



Figure 5. Comparison between calculated results of the empirical Equation 22 and the normative formula of Wuhan Institute of Hydraulic and Electric Engineering

Although there is no direct data to determine the rationality of the calculation results Equation 22 and the formula of Wuhan Institute of Hydraulic and Electric Engineering, it can be concluded that the incipient velocity of granular sediment in the flow with great dimensionless water depth calculated by the formula of Wuhan Institute of Hydraulic and Electric Engineering is certainly higher than the actual situation according to the data of the physical characteristics and environment parameters of the shelf dunes (Zhuang et al., 2004). The area where the depth of water is from 132 to 162 $\mathrm{m}$ at continental shelf of the east china sea collected by Zhuang et al. (2004) is taken as the example to verify this claim and there are sand waves with a wavelength of $5 \sim 25 \mathrm{~m}$ and a wave height of $0.5 \sim 2 \mathrm{~m}$. In addition, the sediment particle sizes are between 0.125 and $0.188 \mathrm{~mm}$ and the local maximum flow velocity is between 0.4 and $0.9 \mathrm{~m} / \mathrm{s} \mathrm{in}$ this area. According to the formula of Wuhan Institute of Hydraulic and Electric Engineering, the incipient velocity of sediment is between 1.43 and $1.91 \mathrm{~m} / \mathrm{s}$ in this area, while the incipient velocity of sediment calculated by Equation 22 is between 0.58 and $0.687 \mathrm{~m} / \mathrm{s}$. Obviously, the incipient velocity of sediment calculated by the formula of Wuhan Institute of Hydraulic and Electric Engineering is higher than the local maximum flow velocity, which indicates that the sediment particles cannot suspended 
and there are no sand waves. It follows that the calculation results of Equation 22 are more reasonable in this situation, because the local maximum flow velocity can reach the incipient condition of sediment in this area according to Equation 22. According to the above analysis, Equation 22 proposed in this paper is more credible than the normative formula of Wuhan Institute of Hydraulic and Electric Engineering when they are used to calculate the incipient velocity of granular sediment in the flow with great dimensionless water depth.

\section{Accuracy verification of this empirical formula}

In the study, the calculation results of the empirical formula were compared with the field measurement data collected by Brownlie (1981) to verify the accuracy of this empirical formula proposed in this paper. Firstly, the field measurement data collected from the extant studies which included Atchafalaya River Data of Toffaleti (1968), South American River \& Canal Data of NEDECO (1973), Red River Data of Toffaleti (1968), and Rio Grande River Data of Nordin and Beverage (1965), in which the dimensionless water depth $(H / d)$ was less than $10^{4}$. The calculated results and the collected field measurement data were listed in Table 3.

Table 3. Comparisons with extant experimental data (1)

\begin{tabular}{|c|c|c|c|c|c|c|c|}
\hline $\begin{array}{c}\text { Rate of } \\
\text { flow }\left(\mathrm{m}^{3} / \mathrm{s}\right)\end{array}$ & $\begin{array}{l}\text { River } \\
\text { width } \\
(m)\end{array}$ & $\begin{array}{l}\text { Water } \\
\text { depth } \\
(m)\end{array}$ & $\begin{array}{c}d \\
(m m)\end{array}$ & $\begin{array}{c}\text { Sediment } \\
\text { concentration } \\
(\text { ppm })\end{array}$ & $\begin{array}{l}\text { Extant } \\
\text { data } \\
(\mathrm{m} / \mathrm{s})\end{array}$ & $\begin{array}{c}\text { Calculated } \\
\text { velocity }(m / s)\end{array}$ & Data sources \\
\hline 1073176 & 313.94 & 6.889 & 0.089 & 4.31 & 0.396 & 0.416 & \multirow{4}{*}{$\begin{array}{c}\text { Atchafalaya River Data of } \\
\text { Toffaleti (1968) }\end{array}$} \\
\hline 843816 & 310.89 & 6.431 & 0.106 & 2.80 & 0.322 & 0.331 & \\
\hline 719226 & 307.85 & 6.248 & 0.096 & 8.95 & 0.374 & 0.319 & \\
\hline 637110 & 307.85 & 6.218 & 0.137 & 5.60 & 0.333 & 0.359 & \\
\hline 51000 & 93 & 1.8 & 0.12 & 2.92 & 0.305 & 0.282 & $\begin{array}{c}\text { South American River \& } \\
\text { Canal Data of NEDECO } \\
\text { (1973) }\end{array}$ \\
\hline 206707 & 159.41 & 3.505 & 0.103 & 7.88 & 0.370 & 0.297 & $\begin{array}{l}\text { Red River Data of } \\
\text { Toffaleti (1968) }\end{array}$ \\
\hline 2859.9 & 25.603 & 0.369 & 0.396 & 0 & 0.303 & 0.324 & \multirow{2}{*}{$\begin{array}{c}\text { Rio Grande River Data of } \\
\text { Nordin and Beverage } \\
(1965)\end{array}$} \\
\hline 2944.8 & 43.282 & 0.262 & 0.343 & 5 & 0.262 & 0.272 & \\
\hline & & 0.1192 & 0.102 & & 0.262 & 0.233 & Vanoni (1965) \\
\hline
\end{tabular}

Then the field experimental data in which the dimensionless water depth $(H / d)$ was approximately $10^{4}$ were collected as the correlation data with the calculated results by the empirical formula. The calculated results and the collected field measurement data were listed in Table 4.

It can be seen from Table 3 that when the sediment concentrations are less than or equal to 5 PPM the calculation results by this empirical formula are in good agreement with the data collected from extant studies generally, i.e., Rio Grande River Data of Nordin and Beverage (1965) and South American River \& Canal Data of NEDECO (1973). While the incipient velocity of sediment calculated by this empirical formula is lower than the collected field measurement data when the sediment concentrations are more than 5 PPM and approach 10 PPM, for instance, Red River Data of Toffaleti 
(1968), because the hydrodynamic condition is considered to have exceeded the incipient condition of sediment according to the analysis of sediment transport and the distribution of suspended sediment concentration in the fluid when the sediment particles begin to suspend (Ted et al., 1974), when the sediment concentrations approach 10 PPM. It can be seen from Table 4 that the empirical formula can work well when it is used to calculate the incipient of granular sediment in the flow with high dimensionless water depth. Figure 6 depicts that the calculated values calculated by Equation 22 and the $20 \%$ error lines against measured data.

Table 4. Comparisons with extant experimental data (2)

\begin{tabular}{c|c|c|c|c|c|c}
\hline H/D & $\begin{array}{c}\text { Water } \\
\text { depth }(\boldsymbol{m})\end{array}$ & $\begin{array}{c}\boldsymbol{d} \\
(\boldsymbol{m} \boldsymbol{m})\end{array}$ & $\begin{array}{c}\boldsymbol{\rho}_{\boldsymbol{s}} \\
\left(\boldsymbol{k} \boldsymbol{g} / \boldsymbol{m}^{3}\right)\end{array}$ & $\begin{array}{c}\text { Extant data } \\
(\boldsymbol{m} / \mathbf{s})\end{array}$ & $\begin{array}{c}\text { Calculated } \\
\text { velocity }(\boldsymbol{m} / \boldsymbol{s})\end{array}$ & Data sources \\
\hline 1700.526 & 0.3231 & 0.19 & 1.3 & 0.24 & 0.231 & \\
1604.211 & 0.3048 & 0.19 & 1.3 & 0.232 & 0.229 & Simons, Bishop and \\
1027.407 & 0.2774 & 0.18 & 1.56 & 0.255 & 0.253 & Richardson (1965) \\
1099.286 & 0.3078 & 0.24 & 1.67 & 0.293 & 0.261 & \\
\hline 1700.526 & 0.3241 & 0.19 & 2.65 & 0.24 & 0.231 & \\
1492.105 & 0.2835 & 0.19 & 2.65 & 0.264 & 0.226 & Guy et al. (1966) \\
1460 & 0.2774 & 0.19 & 2.65 & 0.255 & 0.225 & \\
\hline
\end{tabular}



Figure 6. Comparison between calculated results and measured results 


\section{Conclusion}

In this paper, the incipient condition of the granular sediment in the flow with great dimensionless water depth was studied by the method of flume experiment and data fitting. Firstly, the similarity condition between experimental flow and prototype flow with great dimensionless water depth was analysed firstly. Then based on the above analysis, the boundary layer momentum thickness was introduced instead of water depth due to the limitation of the flume experiments. Subsequently, the flume experiment results and a series of extant data were collected and calculated to derive the formula for the incipient velocity of granular sediment in the flow with great dimensionless water depth. The conclusions of this study can be summarized as follows:

The similarity condition between the experimental flow and the prototype flow with great dimensionless water depth is that the ratio of water depth and the particle size of sediment $(H / d$, which is considered as the dimensionless water depth in this paper) in experimental flow is the same with that in prototype flow with great dimensionless water depth, based on the logarithmic velocity distribution law.

Water depth cannot be used as a direct variable in the formula for the incipient condition of the granular sediment in the flow with great dimensionless water depth due to the limitation of flume experiment, which should be replaced by the boundary layer momentum thickness.

An empirical formula for the incipient velocity for the granular sediment in great dimensionless water depth was proposed by introducing boundary layer momentum thickness as an immediate variable. The formula takes boundary layer momentum thickness, particle size and the proportion of sediment and fluid as the main variables. Compared with the normative formula of Wuhan Institute of Hydraulic and Electric Engineering, the increasing trend of the incipient velocities of the granular sediments in the flow with great dimensionless water depth calculated by the two formulas are similar with each other when $H / d \leq 1 \times 10^{4}$, and all increase slowly, but when $H / d>1 \times 10^{4}$, the increasing trend of the incipient velocities of the granular sediments calculated by the formula proposed in this paper is much slower than that by the normative formula of Wuhan Institute of Hydraulic and Electric Engineering. Finally, the accuracy of the proposed formula is verified.

\section{Recommendations for future researches}

Firstly, the viscous force between sediment particles should be considered in future researches. Because the sediment particles behave in a cohesive manner when the particle size is less than $500 \mu \mathrm{m}$, moreover, the viscous force becomes the main resistance to the initial motion of sediment, and the effect of gravity on the initial motion of sediment can be neglected, when the particle size is less than $60 \mu \mathrm{m}$. But there is no convincing result about the incipient condition of cohesive sediment. In future researches, the concept of sediment fluidization can be introduced to study on the incipient conditions of cohesive sediment, and different sediment fluidization level will cause the variation of starting velocity.

Secondly, the application condition and the form of the formula need further study. Because that the research results in this paper are based on logarithmic velocity distribution, which is reliable for the unidirectional flow. However, the applicability of the condition in complex flow field, such as wave or tide, has yet to be verified. 
Acknowledgements. This work was financially supported by the National Key Research and Development Program of China (Grant number: 2016YFC0402607). We are also grateful to the anonymous reviewers for their constructive comments and suggestions, which have helped improve the manuscript significantly.

\section{REFERENCES}

[1] Bai, Y. C., Xu, D., Zhang, X. Y. (2005): Experimental study on flow turbulence characteristics of open channel on alluvial bed and its relation to incipient motion of bed sediment. - Progress in Natural Science 15(4): 439-445 (in Chinese).

[2] Balucani, U., Brodholt, J. P., Vallauri, R. (1996): Dynamical properties of liquid water. Journal of Physics: Condensed Matter 8(47): 9269-9274 (https://doi.org/10.1088/09538984/8/47/014).

[3] Beheshti, A. A., Ataie-Ashtiani, B. (2008): Analysis of threshold and incipient conditions for sediment movement. - Coastal Engineering 55(5): 423-430 (https://doi.org/10.1016/j.coastaleng.2008.01.003).

[4] Bennett, S. J., Best, J. L. (1995): Mean flow and turbulence structure over fixed, two-dimensional dunes: implications for sediment transport and bedform stability. Sedimentology 42(3): 491-5123 (https://doi.org/10.1111/j.1365-3091.1995.tb00386.x).

[5] Berlamont, J., Ockenden, M., Toorman, E., Winterwerp, J. (1993): The characterisation of cohesive sediment properties. - Coastal Engineering 21(1): 105-128 (https://doi.org/10.1016/0378-3839(93)90047-c).

[6] Bohorquez, P., Fernandez-Feria, R. (2008): Transport of suspended sediment under the dam-break flow on an inclined plane bed of arbitrary slope. - Hydrol. Process. 22: 26152633 (https://doi.org/10.1002/hyp.6858).

[7] Brownlie, W. R. (1981): Compilation of alluvial channel data: laboratory and field. Rep. No. KH-R-43B, W. M. Keck Lab. of Hydr. and Water Resources., California Institute of Technology, Pasadena, California.

[8] Casey, H. J. (1935): Ueber Geschiebebewegung (On Bed Load, in German). - Mitt. Preuss. Versuchsanstalt f. Wasserbau u. Schiffbau, Berlin.

[9] Chien, N., Wan, Z. (1999): Mechanics of Sediment Transport. - ASCE Press, Reston, VA (https://doi.org/10.1061/9780784404003).

[10] Dornbrack, A., Schumann, U. (1993): Numerical simulation of turbulent convective flow over wavy terrain. - Boundary-Layer Meteorology 65(4): 323-355 (https://doi.org/10.1007/bf00707032).

[11] Costello, W. R. (1974): Development of Bed Configuration in Coarse Sands. - Report 74-1. Department of Earth and Planetary Science. Massachusetts Institute of Technology, Cambridge, Massachusetts.

[12] Davies, T. R. (1971): Summary of experimental data for flume tests over fine sand. Department of Civil Engineering, University of Southampton.

[13] Dou, G. (1960): Discussion on the incipient velocity of sediment. - Shuili Xuebao 4: 4460 (in Chinese).

[14] Drake, T. G., Calantoni, J. (2001): Discrete particle model for sheet flow sediment transport in the nearshore. - Journal of Geophysical Research Atmospheres 106(C9): 19858-19868 (https://doi.org/10.1029/2000jc000611).

[15] Falcão, A. F. O., Henriques, J. C. C. (2014): Model-prototype similarity of oscillatingwater-column wave energy converters. - International Journal of Marine Energy 6: 18-34 (https://doi.org/10.1016/j.ijome.2014.05.002).

[16] Ferro, V. (1999): Friction factor for gravel-bed channel with high boulder concentration. - J. Hydraul. Eng. 125(7): 771-778 (https://doi.org/10.1061/(asce)07339429(1999)125:7(771)). 
[17] Francisco, J. M. S. (2014): Shear velocity criterion for incipient motion of sediment. Water Science and Engineering 7(2): 183-193.

[18] Geiger, S. L., Durnford, D. S. (2000): Infiltration in homogeneous sands and a mechanistic model of unstable flow. - Soil Science Society of America Journal 64(2): 460-469 (https://doi.org/10.2136/sssaj2000.642460x).

[19] Guy, H. P., Simons, D. B., \& Richardson, E. V. (1966): Summary of alluvial channel data from flume experiments, 1956-61: US Geol. Survey Prof. Paper 462(1): 11-196 (https://doi.org/10.3133/pp462i).

[20] Han, Q. (1982): Characteristics of incipient sediment motion and incipient velocity. Journal of Sediment Research 2: 11-26 (in Chinese).

[21] He, W. D., Fang, Z., Yang, J. R., Cao, S. Y. (2002): Study on incipient velocity of sediment. - Shuili Xuebao 33(10): 51-56 (in Chinese).

[22] Hokenson, G. J. (1977): Consistent integral thickness utilization for boundary layers with transverse curvature. - AIAA Journal 15(4): 597-600 (https://doi.org/10.2514/3.7350).

[23] Ho, P. Y. (1939): Abhängigkeit der Geschiebebewegung von der Kornform und der Temperatur. - Preussische Versuchsanstalt für Wasser-, Erdund Schiffbau 37: 43.

[24] Huang, Z. W., Lu, B. W., Wu, N. H. (2012): Study on incipient velocity of sediment in model test. - Jiangxi Hydraulic Science \& Technology 38(1): 16-19 (in Chinese).

[25] Jain, A. K., Juans, R. (2009): Preferential mode of gas invasion in sediments: grain-scale model of coupled multiphase fluid flow and sediment mechanics. - JGR Solid Earth 114: B08101 (https://doi.org/10.1029/2008jb006002).

[26] Jonsson, I. G. (1966): Wave boundary layer and friction factors. - Proc.10th Coastal Eng. Conf. ASCE, pp. 127-148 (https://doi.org/10.1061/9780872620087.010).

[27] Kramer, H. (1935): Sand mixtures and sand movement in fluvial models. - Trans. Am. Soc. Civ. Eng. 100(1909): 798-838.

[28] Li, W., Cao, S., Liu, S. (2006): The law of sand transport of Yichang Changjiang station. - Journal of Sichuan University (Engineering Science Edition) 38(1): 26-29 (in Chinese).

[29] Lu, J. (1991): Study on incipient velocity of sediment transport in Yangtze River. Journal of Yangtze River Scientific Research Institute 8(4): 57-64 (in Chinese).

[30] Lumborg, U., Windelin, A. (2003): Hydrography and cohesive sediment modelling: application to the Rømø Dyb tidal area. - Journal of Marine Systems 38(3): 287-303 (https://doi.org/10.1016/s0924-7963(02)00247-6).

[31] Luo, X., Yang, F. (2011): Derivation of incipient velocity for uniform sediment based on the concept of the angle of repose. - 2011 International Symposium on Water Resource and Environmental Protection. IEEE Xplore 2011 (https://doi.org/10.1109/icicta.2011.31).

[32] Mao, J., Dai, H., He, W. (2011): Calculating incipient velocity of non-uniform sediment through stress analysis. - International Symposium on Water Resource and Environmental Protection, IEEE (https://doi.org/10.1109/iswrep.2011.5893080).

[33] Mavis, F. T., Ho, C., Tu, Y. C., Liu, T. Y., \& Soucek, E. (1935): The transportation of detritus by flowing water (I). - Iowa University Studies in Engineering, Bulletin 11.

[34] Meftah, M. B., Mossa, M. (2016): A modified log-law of flow velocity distribution in partly obstructed open channels. - Environmental Fluid Mechanics 16(2): 453-479 (https://doi.org/10.1007/s10652-015-9439-7).

[35] Mehta, A. J. (1984): Characterization of Cohesive Sediment Properties and Transport Processes in Estuaries. - In: Mehta, A. J. (ed.) Estuarine Cohesive Sediment Dynamics, Lecture Notes on Coastal and Estuarine Studies, Volume 14. Springer, New York, pp. 290-325 (https://doi.org/10.1029/ln014p0290).

[36] Mehta, A. J. (1989): On estuarine cohesive sediment suspension behaviour. - JGR Oceans 94(C10): 14303-14314 (https://doi.org/10.1029/jc094ic10p14303).

[37] Meyer-Peter, E., \& Muller, R. (1948): Formulas for bed-load transport, - Proceedings of the 2nd Meeting of the International Association for Hydraulic Structures Research. International Association of Hydraulic Research Delft. 
[38] Mianael, S. J., Keshavarzi, A. R. (2010): Study of near bed stochastic turbulence and sediment entrainment over the ripples at the bed of open channel using image processing technique. - Stochastic Environmental Research and Risk Assessment 24(5): 591-598.

[39] Mutter, D. G. (1971): A Flume Study of Alluvial Bed Configurations. - Masters thesis submitted to the Faculty of Graduate Studies, University of Alberta.

[40] NEDECO (1973): Rio Magdalena and Canal del Dique Project. Mission Tecnica Colombo-Holandesa. - NEDECO Report, NEDECO, The Hague, The Netherlands.

[41] Nie, R., Liu, X. (2004): Comparison study on incipient motion conditions for cohesive sediment. - Advances in Water Science 15(5): 584-587 (in Chinese).

[42] Nikuradse, J. (1933): Laws of flow in rough pipes (1950 translation). - National Advisory Committee on Aeronautics. Technical Memorandum No 1292, Washington, DC.

[43] Niven, R. K. (2010): Minimization of a free-energy-like potential for non-equilibrium flow systems at steady state. - Philosophical Transactions of The Royal Society B Biological Sciences 365(1545): 1323-31 (https://doi.org/10.1098/rstb.2009.0296).

[44] Nordin, C. F., \& Beverage, J. P. (1965): Sediment transport in the Rio Grande. - New Mexico. US Government Printing Office (https://doi.org/10.3133/pp462f).

[45] Nordin, C. F. (1976): Flume studies with fine and coarse sands (No. 76-762). - US Geological Survey, (https://doi.org/10.3133/ofr76762).

[46] O'Brien, M. P. (1936): Notes on the transportation of silt by streams. - Eos, Transactions American Geophysical Union, 17(2), 431-436 (https://doi.org/10.1029/tr017i002p00431).

[47] Paintal, A. S. (1971): Concept of critical shear stress in loose boundary open channels. Journal of Hydraulic Research 9(1): 91-113 (https://doi.org/10.1080/00221687109500339).

[48] Phillips, J. D. (1992): Nonlinear dynamical systems in geomorphology: revolution or evolution. - Geomorphology 5(3-5): 219-229 9 (https://doi.org/10.1016/0169$555 x(92) 90005-9)$.

[49] Pratt, C. J. (1970): Summary of Experimental Data for Flume Tests over 0.49 mm Sand. Department of Civil Engineering, University of Southhampton, Southhampton, England.

[50] Righetti, M., Lucarelli, C. (2007): May the Shields theory be extended to cohesive and adhesive benthic sediments? - J. Geophys. Res. 112: C05039 (https://doi.org/10.1029/2006jc003669).

[51] Robert, C. G., Droppo, I. G., Wharton, G. (2011): Erodibility of cohesive sediment: The importance of sediment properties. - Earth-Science Reviews 105(4): 101-120 (https://doi.org/10.1016/j.earscirev.2011.01.008.

[52] Rijn, L. C. V. (1984): Sediment transport, Part I: bed load transport. - J. Hydraul. Eng. 110(10): 1431-1456.

[53] Roux, J. P. L. (2010): Sediment entrainment under fully developed waves as a function of water depth, boundary layer thickness, bottom slope and roughness. - Sedimentary Geology 223(1): 143-149 (https://doi.org/10.1016/j.sedgeo.2009.11.006).

[54] Sha, Y. (1965): Introduce Sediment Kinematics. - China Industry Press, Beijing).

[55] Simons, D. B. Bishop, A. A., Richardson, E. V. (1965): Total Bed Material Transport. Proc. - Journal of the Hydraulics Division 91(2): 175-191.

[56] Steward, F. R., Tennankore, K. N. (1977): Similarity criterion for a confined swirling jet system. - Symposium (International) on Combustion 16(1): 1593-1609.

[57] Tang, C. (1963): Initial motion law of sediment. - Shuili Xuebao 3: 1-12 (in Chinese).

[58] Taylor, B. D. (1971): Temperature Effects in Alluvial Streams. - W. M. Keck Laboratory Report KH-R-27, California Institute of Technology, Pasadena, Calif..

[59] Toffaleti, F. B. (1968): A Procedure for Computation of the Total River Sand Discharge and Detailed Distribution, Bed to Surface. - Technical Report No. 5, Committee of Channel Stabilization, United States Army Corps of Engineers. 
[60] Vanoni, V. A. (1965): Data used to develop Shields diagram. - In Technical Memorandum 65-2. WM Keck Laboratory of Hydraulics and Water Resources, California Institute of Technology Pasadena (California), USA.

[61] Venditti, J. G., Church, M., Bennett, S. J. (2006): On interfacial instability as a cause of transverse subcritical bed forms. - Water Resour. Res. 42(7): W07423 (https://doi.org/10.1029/2005wr004346).

[62] Wang, T., Liu, X., Huang, E., Nie, R., Cai, B. (2008): Study and comparison on incipient velocity for non-uniform sediment. - Journal of Sichuan University (Engineering Science Edition) 40(1): 16-20 (in Chinese).

[63] Wang, T., Liu, X., Nie, R., Huang, E. (2010): Comparative study on the incipient motion conditions of non-uniform non-cohesive sediment. - Journal of Hydroelectric Engineering 29(6): 126-131 (in Chinese).

[64] West Bengal, Government of. (1965): Study on the Critical Tractive Force Various Grades of Sand. - Annual Report of the River Research Institute, West Bengal, Publication No. 26 Part I, 5-12.

[65] Xie, J. (1981): River Sediment Engineering (Part I). - Water Resources and Electric Power Press, Beijing (in Chinese).

[66] Yalin, M. S., Karahan, E. (1983): On the development of turbulent boundary layer in open channel flows. - Combustion Explosion \& Shock Waves 17(5): 545549(https://doi.org/10.1007/bf00798143).

[67] Yang, S., Hu, J., Wang. X. (2006): Incipient motion of coarse particles in great gradient rivers. - International Journal of Sediment Research 21(3): 220-229.

[68] Yu, G., Lim, S. (2003): Modified manning formula for flow in alluvial channels with $\begin{array}{llllll}\text { sand-beds. } & - & \text { J. } & \text { Hydraul. } & \text { Res. } & \text { 41(6): }\end{array}$ (https://doi.org/10.1080/00221680309506892).

[69] Yu, G., Tan, S. K. (2006): Errors in the bed shear stress as estimated from vertical velocity profile. - Journal of Irrigation and Drainage Engineering 132(5): 490-497 (https://doi.org/10.1061/(asce)0733-9437(2006)132: 5(490)).

[70] Zeng, J., Chen, G., Xiong, S. (2010): Study on incipient velocity of fine sediment in the Qiantang Estuary. - Journal of Waterway and Harbor 31(5): 347-351 (in Chinese).

[71] Zhang, H. (2012): A unified formula for incipient of sediment. - Shuili Xuebao 12(43): 1387-1396 (in Chinese).

[72] Zhang, M., Yu, G. (2017): Critical conditions of incipient motion of cohesive sediments. - Water Resources. Res. 53(9): 7798-7815 (https://doi.org/10.1002/2017wr021066).

[73] Zhang, M., Dolatshah, A., Zhu, W., Yu, G. (2018): Case study on water quality improvement in Xihu Lake through diversion and water distribution. - Water 10(3): 333 (https://doi.org/10.3390/w10030333).

[74] Zhang, R., Xie, J., Chen, W. (1961): River Mechanics. - China Industry Press, Beijing (in Chinese).

[75] Zhuang, Z., Lin, Z., Zhou, J., Liu, Z., Liu, Y. (2004): Environmental conditions for the formation and development of sand dunes (waves) in the continental shelf. - Marine Geology Letters 20(4): 5-10 (in Chinese).

[76] Zou, X., Wang, C., Song, H., Han, Z., Ma, Z. (2017): Experimental measurements of sediment incipient velocity by using B-scan ultrasound imaging device in the water channel.

Measurement

98:

$228-236$ (https://doi.org/10.1016/j.measurement.2016.12.006). 


\section{APPENDIX}

Detailed collected data

\begin{tabular}{|c|c|c|c|c|c|}
\hline$H / d$ & Depth $(m)$ & $d(\mathrm{~mm})$ & Concentration (ppm) & $V_{c}(m / s)$ & Data sources \\
\hline 930.526 & 0.1768 & 0.19 & 1 & 0.22 & \multirow{7}{*}{$\begin{array}{l}\text { Simons, Bishop } \\
\text { and Richardson } \\
\quad(1965)\end{array}$} \\
\hline 705.789 & 0.1341 & 0.19 & 2 & 0.26 & \\
\hline 642.142 & 0.1798 & 0.28 & 1 & 0.269 & \\
\hline 492.766 & 0.2316 & 0.47 & 1.6 & 0.347 & \\
\hline 486.383 & 0.2286 & 0.47 & 2.3 & 0.353 & \\
\hline 480 & 0.2256 & 0.47 & 2.5 & 0.365 & \\
\hline 461.818 & 0.1524 & 0.33 & 3.5 & 0.319 & \\
\hline 350 & 0.189 & 0.54 & \multirow[t]{7}{*}{0.5} & 0.297 & \multirow{7}{*}{$\begin{array}{l}\text { Yalin and Karahar } \\
\text { (1979) ASCE }\end{array}$} \\
\hline 1.151 & 0.0012 & 1 & & 0.215 & \\
\hline 6.276 & 0.0063 & 1 & & 0.289 & \\
\hline 8.369 & 0.0047 & 0.56 & & 0.215 & \\
\hline 64.776 & 0.0065 & 0.1 & & 0.231 & \\
\hline 11.788 & 0.0047 & 0.4 & & 0.212 & \\
\hline 30.254 & 0.0057 & 0.19 & & 0.206 & \\
\hline 39.186 & 0.0055 & 0.14 & & 0.205 & \multirow{22}{*}{$\mathrm{Li}$ and Sun (1965) } \\
\hline 821.428 & 0.115 & 0.14 & & 0.21 & \\
\hline 771.428 & 0.108 & 0.14 & & 0.22 & \\
\hline 857.142 & 0.12 & 0.14 & & 0.2 & \\
\hline 28.5 & 0.057 & 2 & & 0.45 & \\
\hline 30.5 & 0.061 & 2 & & 0.46 & \\
\hline 38.5 & 0.077 & 2 & & 0.47 & \\
\hline 49.5 & 0.099 & 2 & & 0.49 & \\
\hline 48.5 & 0.097 & 2 & & 0.49 & \\
\hline 61.363 & 0.054 & 0.88 & & 0.32 & \\
\hline 45.454 & 0.04 & 0.88 & & 0.3 & \\
\hline 105.263 & 0.04 & 0.38 & & 0.24 & \\
\hline 115.789 & 0.044 & 0.38 & & 0.25 & \\
\hline 155.263 & 0.059 & 0.38 & & 0.27 & \\
\hline 168.421 & 0.064 & 0.38 & & 0.24 & \\
\hline 215.384 & 0.056 & 0.26 & & 0.2 & \\
\hline 192.307 & 0.05 & 0.26 & & 0.24 & \\
\hline 234.615 & 0.061 & 0.26 & & 0.21 & \\
\hline 188.461 & 0.049 & 0.26 & & 0.23 & \\
\hline 196.153 & 0.051 & 0.26 & & 0.24 & \\
\hline 271.428 & 0.038 & 0.14 & & 0.19 & \\
\hline 264.285 & 0.037 & 0.14 & & 0.2 & \\
\hline 278.730 & 0.0878 & 0.32 & 0.2 & 0.243 & \multirow{6}{*}{$\begin{array}{l}\text { Govt. of West } \\
\text { Bengal (1965) }\end{array}$} \\
\hline 344.444 & 0.1085 & 0.32 & 0.7 & 0.271 & \\
\hline 391.746 & 0.1234 & 0.32 & 1 & 0.283 & \\
\hline 402.539 & 0.1268 & 0.32 & 1.1 & 0.288 & \\
\hline 427.619 & 0.1347 & 0.32 & 1.1 & 0.285 & \\
\hline 464.444 & 0.1463 & 0.32 & 1.3 & 0.279 & \\
\hline
\end{tabular}




\begin{tabular}{|c|c|c|c|c|c|}
\hline 480 & 0.1512 & 0.32 & 1.8 & 0.282 & \\
\hline 506.984 & 0.1597 & 0.32 & 2.6 & 0.294 & \\
\hline 13.618 & 0.0335 & 2.46 & 1.6 & 0.447 & \multirow{3}{*}{ Casey (1935) } \\
\hline 47.561 & 0.117 & 2.46 & 1.6 & 0.482 & \\
\hline 47.439 & 0.1167 & 2.46 & 0.019 & 0.454 & \\
\hline 290.196 & 0.148 & 0.51 & 0.094 & 0.288 & \multirow{5}{*}{ Costello (1974) } \\
\hline 288.054 & 0.1495 & 0.52 & 1.679 & 0.311 & \\
\hline 264.167 & 0.1585 & 0.6 & 0.473 & 0.32 & \\
\hline 239.394 & 0.158 & 0.66 & 0.819 & 0.324 & \\
\hline 194.937 & 0.154 & 0.79 & 0.764 & 0.357 & \\
\hline 2032 & 0.3048 & 0.15 & 0.8 & 0.181 & \multirow{2}{*}{ Davies (1971) } \\
\hline 2032 & 0.3048 & 0.15 & 0.9 & 0.21 & \\
\hline 706.316 & 0.1342 & 0.19 & 2 & 0.258 & \multirow{13}{*}{$\begin{array}{l}\text { Guy, Simons and } \\
\text { Richardson (1966) }\end{array}$} \\
\hline 642.143 & 0.1798 & 0.28 & 1 & 0.269 & \\
\hline 663.778 & 0.2987 & 0.45 & 0.7 & 0.242 & \\
\hline 548.667 & 0.2469 & 0.45 & 1.2 & 0.24 & \\
\hline 541.778 & 0.2438 & 0.45 & 0.7 & 0.242 & \\
\hline 392.889 & 0.1768 & 0.45 & 0.7 & 0.238 & \\
\hline 392.667 & 0.1767 & 0.45 & 1.4 & 0.252 & \\
\hline 223.556 & 0.1006 & 0.45 & 1 & 0.225 & \\
\hline 337.527 & 0.3139 & 0.93 & 0.4 & 0.404 & \\
\hline 330.968 & 0.3078 & 0.93 & 0.4 & 0.455 & \\
\hline 492.766 & 0.2316 & 0.47 & 0.4 & 0.347 & \\
\hline 486.383 & 0.2286 & 0.47 & 0.4 & 0.353 & \\
\hline 480 & 0.2256 & 0.47 & 0.4 & 0.365 & \\
\hline 69.521 & 0.2176 & 3.13 & 0.1 & 0.581 & \multirow{17}{*}{ Ho (1939) } \\
\hline 83.833 & 0.2624 & 3.13 & 0.45 & 0.656 & \\
\hline 45.271 & 0.1417 & 3.13 & 0.73 & 0.547 & \\
\hline 58.339 & 0.1826 & 3.13 & 1.11 & 0.602 & \\
\hline 67.188 & 0.2103 & 3.13 & 1.55 & 0.631 & \\
\hline 78.690 & 0.2463 & 3.13 & 2.89 & 0.689 & \\
\hline 33.195 & 0.1039 & 3.13 & 0.97 & 0.478 & \\
\hline 45.367 & 0.142 & 3.13 & 0.54 & 0.59 & \\
\hline 50.825 & 0.2216 & 4.36 & 0.089 & 0.633 & \\
\hline 56.491 & 0.2463 & 4.36 & 0.19 & 0.664 & \\
\hline 35.573 & 0.1551 & 4.36 & 0.26 & 0.61 & \\
\hline 42.293 & 0.1844 & 4.36 & 0.66 & 0.667 & \\
\hline 46.559 & 0.203 & 4.36 & 0.97 & 0.698 & \\
\hline 50.183 & 0.2188 & 4.36 & 1.79 & 0.734 & \\
\hline 35.525 & 0.2231 & 6.28 & 0.16 & 0.724 & \\
\hline 16.891 & 0.1061 & 6.28 & 1.12 & 0.714 & \\
\hline 18.203 & 0.1094 & 6.01 & 1.3 & 0.692 & \\
\hline 29.019 & 0.1213 & 4.18 & 1.2 & 0.65 & \multirow{4}{*}{ Mavis et al. (1937) } \\
\hline 30.837 & 0.1289 & 4.18 & 1.3 & 0.695 & \\
\hline 31.794 & 0.1329 & 4.18 & 1.3 & 0.715 & \\
\hline 22.608 & 0.0945 & 4.18 & 1.3 & 0.623 & \\
\hline
\end{tabular}




\begin{tabular}{|c|c|c|c|c|c|}
\hline 24.067 & 0.1006 & 4.18 & 0.8 & 0.656 & \\
\hline 25.383 & 0.1061 & 4.18 & 0.7 & 0.660 & \\
\hline 25.813 & 0.1079 & 4.18 & 1.3 & 0.658 & \\
\hline 26.244 & 0.1097 & 4.18 & 1.2 & 0.69 & \\
\hline 26.459 & 0.1106 & 4.18 & 2.3 & 0.713 & \\
\hline 25.608 & 0.0799 & 3.12 & 0.9 & 0.531 & \\
\hline 26.955 & 0.0841 & 3.12 & 1.1 & 0.554 & \\
\hline 28.045 & 0.0875 & 3.12 & 2.2 & 0.567 & \\
\hline 30.16 & 0.0941 & 3.12 & 1.9 & 0.568 & \\
\hline 30.481 & 0.0951 & 3.12 & 2.8 & 0.622 & \\
\hline 21.186 & 0.0661 & 3.12 & 2.9 & 0.532 & \\
\hline 22.179 & 0.0692 & 3.12 & 2 & 0.539 & \\
\hline 16.410 & 0.0512 & 3.12 & 2.8 & 0.523 & \\
\hline 15.833 & 0.0494 & 3.12 & 2.8 & 0.552 & \\
\hline 33.054 & 0.0671 & 2.03 & 1.3 & 0.465 & \\
\hline 35.419 & 0.0719 & 2.03 & 1.2 & 0.481 & \\
\hline 37.537 & 0.0762 & 2.03 & 3 & 0.501 & \\
\hline 26.552 & 0.0539 & 2.03 & 2 & 0.46 & \\
\hline 28.818 & 0.0585 & 2.03 & 1.8 & 0.515 & \\
\hline 34.61 & 0.0488 & 1.41 & 2.8 & 0.366 & \\
\hline 24.584 & 0.0917 & 3.73 & 1 & 0.563 & \\
\hline 26.971 & 0.1006 & 3.73 & 1.8 & 0.581 & \\
\hline 28.204 & 0.1052 & 3.73 & 2.3 & 0.624 & \\
\hline 30.08 & 0.1122 & 3.73 & 2.9 & 0.641 & \\
\hline 17.48 & 0.0652 & 3.73 & 1.4 & 0.539 & \\
\hline 19.035 & 0.071 & 3.73 & 1.3 & 0.56 & \\
\hline 20.429 & 0.0762 & 3.73 & 2.3 & 0.603 & \\
\hline 32.679 & 0.0549 & 1.68 & 1.9 & 0.402 & \\
\hline 23.75 & 0.0399 & 1.68 & 2.7 & 0.386 & \\
\hline 41.933 & 0.1128 & 2.69 & 1.133 & 0.497 & $\begin{array}{l}\text { Meyer-Peter and } \\
\text { Muller (1948) }\end{array}$ \\
\hline 232.308 & 0.0604 & 0.26 & 3 & 0.127 & \\
\hline 233.462 & 0.0607 & 0.26 & 2 & 0.126 & Mutter (1971) \\
\hline 249.615 & 0.0649 & 0.26 & 2 & 0.143 & \\
\hline 1280 & 0.32 & 0.25 & 0.8 & 0.369 & Nordin (1076) \\
\hline 532.456 & 0.607 & 1.14 & 2.9 & 0.515 & 1901010 (19/0) \\
\hline 855 & 0.3078 & 0.36 & 1.9 & 0.36 & O'Brien \\
\hline 868.611 & 0.3127 & 0.36 & 1.9 & 0.348 & ODHen (1950) \\
\hline 4.324 & 0.096 & 22.2 & 0.071 & 0.807 & \\
\hline 4.739 & 0.1052 & 22.2 & 0.074 & 0.883 & \\
\hline 5.149 & 0.1143 & 22.2 & 0.039 & 0.949 & \\
\hline 5.631 & 0.125 & 22.2 & 0.029 & 0.967 & \\
\hline 5.946 & 0.132 & 22.2 & 0.012 & 1.079 & Paintal (1971) \\
\hline 6.604 & 0.1466 & 22.2 & 0.058 & 1.057 & \\
\hline 6.73 & 0.1494 & 22.2 & 0.155 & 1.141 & \\
\hline 7.14 & 0.1585 & 22.2 & 0.171 & 1.173 & \\
\hline 7.347 & 0.1631 & 22.2 & 0.396 & 1.235 & \\
\hline
\end{tabular}




\begin{tabular}{|c|c|c|c|c|}
\hline 7.69 & 0.1707 & 22.2 & 0.374 & 1.27 \\
\hline 8.239 & 0.1829 & 22.2 & 0.632 & 1.287 \\
\hline 8.401 & 0.1865 & 22.2 & 0.706 & 1.329 \\
\hline 9.131 & 0.2027 & 22.2 & 1.572 & 1.376 \\
\hline 6.455 & 0.1433 & 22.2 & 0.88 & 1.016 \\
\hline 6.455 & 0.1433 & 22.2 & 1.009 & 0.973 \\
\hline 7.14 & 0.1585 & 22.2 & 1.214 & 1.075 \\
\hline 7.414 & 0.1646 & 22.2 & 1.144 & 1.223 \\
\hline 8.306 & 0.1844 & 22.2 & 2.16 & 1.277 \\
\hline 6.455 & 0.1433 & 22.2 & 1.683 & 0.994 \\
\hline 6.28 & 0.1387 & 22.2 & 1.1791 & 0.849 \\
\hline 7.072 & 0.157 & 22.2 & 1.683 & 0.939 \\
\hline 10.201 & 0.0811 & 7.95 & 0.189 & 0.764 \\
\hline 6.742 & 0.0536 & 7.95 & 0.004 & 0.532 \\
\hline 10.767 & 0.0856 & 7.95 & 0.061 & 0.724 \\
\hline 8.516 & 0.0677 & 7.95 & 0.039 & 0.595 \\
\hline 12.264 & 0.0975 & 7.95 & 0.574 & 0.794 \\
\hline 5.522 & 0.0439 & 7.95 & 0.005 & 0.649 \\
\hline 8.201 & 0.0652 & 7.95 & 0.012 & 0.713 \\
\hline 13.421 & 0.1067 & 7.95 & 0.185 & 0.755 \\
\hline 13.648 & 0.1085 & 7.95 & 0.222 & 0.857 \\
\hline 9.623 & 0.0765 & 7.95 & 0.006 & 0.668 \\
\hline 11.27 & 0.0896 & 7.95 & 0.025 & 0.743 \\
\hline 12.956 & 0.103 & 7.95 & 1.1669 & 0.842 \\
\hline 15.409 & 0.1225 & 7.95 & 1.55 & 0.91 \\
\hline 14.566 & 0.1158 & 7.95 & 0.202 & 0.856 \\
\hline 5.786 & 0.046 & 7.95 & 0.007 & 0.741 \\
\hline 7.208 & 0.0573 & 7.95 & 0.006 & 0.568 \\
\hline 6.704 & 0.0533 & 7.95 & 0.001 & 0.535 \\
\hline 5.371 & 0.0427 & 7.95 & 0.026 & 0.624 \\
\hline 5.824 & 0.0463 & 7.95 & 0.01 & 0.602 \\
\hline 6.138 & 0.0488 & 7.95 & 0.008 & 0.635 \\
\hline 6.667 & 0.053 & 7.95 & 0.011 & 0.585 \\
\hline 3.61 & 0.0287 & 7.95 & 0.001 & 0.54 \\
\hline 5.522 & 0.0439 & 7.95 & 0.066 & 0.692 \\
\hline 11.597 & 0.0922 & 7.95 & 0.003 & 0.504 \\
\hline 10.239 & 0.0814 & 7.95 & 0.004 & 0.495 \\
\hline 9.925 & 0.0789 & 7.95 & 0 & 0.393 \\
\hline 10.893 & 0.0866 & 7.95 & 0.001 & 0.483 \\
\hline 12.654 & 0.1006 & 7.95 & 0.005 & 0.493 \\
\hline 43.64 & 0.1091 & 2.5 & 2.5 & 0.591 \\
\hline 38.16 & 0.0954 & 2.5 & 0.192 & 0.497 \\
\hline 33.04 & 0.0826 & 2.5 & 0.032 & 0.388 \\
\hline 40.24 & 0.1006 & 2.5 & 0.686 & 0.659 \\
\hline 32.92 & 0.0823 & 2.5 & 0.092 & 0.508 \\
\hline 16.84 & 0.0421 & 2.5 & 0.002 & 0.419 \\
\hline
\end{tabular}




\begin{tabular}{|c|c|c|c|c|c|}
\hline 19.88 & 0.0497 & 2.5 & 0.01 & 0.405 & \\
\hline 22.8 & 0.057 & 2.5 & 0.014 & 0.435 & \\
\hline 28.04 & 0.0701 & 2.5 & 0.387 & 0.442 & \\
\hline 16.84 & 0.0421 & 2.5 & 0.002 & 0.443 & \\
\hline 24.28 & 0.0607 & 2.5 & 0.01 & 0.408 & \\
\hline 26.84 & 0.0671 & 2.5 & 0.02 & 0.554 & \\
\hline 33.28 & 0.0832 & 2.5 & 0.463 & 0.506 & \\
\hline 26.84 & 0.0671 & 2.5 & 0.266 & 0.425 & \\
\hline 18.4 & 0.046 & 2.5 & 0.012 & 0.404 & \\
\hline 23.04 & 0.0576 & 2.5 & 0.145 & 0.484 & \\
\hline 15.72 & 0.0393 & 2.5 & 0.002 & 0.441 & \\
\hline 637.656 & 0.3048 & 0.478 & 0.77 & 0.283 & \multirow{15}{*}{ Pratt (1970) } \\
\hline 637.659 & 0.3048 & 0.478 & 0.506 & 0.267 & \\
\hline 637.656 & 0.3048 & 0.478 & 0.28 & 0.248 & \\
\hline 637.656 & 0.3048 & 0.478 & 1.37 & 0.311 & \\
\hline 637.656 & 0.3048 & 0.478 & 2.9 & 0.338 & \\
\hline 318.828 & 0.1524 & 0.478 & 2.89 & 0.272 & \\
\hline 318.828 & 0.1524 & 0.478 & 1.54 & 0.253 & \\
\hline 318.828 & 0.1524 & 0.478 & 0.582 & 0.236 & \\
\hline 318.828 & 0.1524 & 0.478 & 0.278 & 0.217 & \\
\hline 956.485 & 0.4572 & 0.478 & 0.12 & 0.247 & \\
\hline 956.485 & 0.4572 & 0.478 & 0.262 & 0.259 & \\
\hline 956.485 & 0.4572 & 0.478 & 0.146 & 0.271 & \\
\hline 956.485 & 0.4572 & 0.478 & 0.307 & 0.283 & \\
\hline 956.485 & 0.4572 & 0.478 & 0.632 & 0.304 & \\
\hline 956.485 & 0.4572 & 0.478 & 1.73 & 0.336 & \\
\hline 283.72 & 0.061 & 0.215 & 0.184 & 0.229 & \multirow{20}{*}{ Taylor (1971) } \\
\hline 283.72 & 0.061 & 0.215 & 0.737 & 0.229 & \\
\hline 283.72 & 0.061 & 0.215 & 0.049 & 0.213 & \\
\hline 283.72 & 0.061 & 0.215 & 0.143 & 0.213 & \\
\hline 283.72 & 0.061 & 0.215 & 0.003 & 0.198 & \\
\hline 283.72 & 0.061 & 0.215 & 0.01 & 0.198 & \\
\hline 21.423 & 0.0602 & 2.81 & 0.215 & 0.502 & \\
\hline 21.423 & 0.0602 & 2.81 & 0.051 & 0.502 & \\
\hline 17.864 & 0.0502 & 2.81 & 1.056 & 0.638 & \\
\hline 21.423 & 0.0602 & 2.81 & 0.549 & 0.532 & \\
\hline 21.423 & 0.0602 & 2.81 & 0.05 & 0.487 & \\
\hline 21.423 & 0.0602 & 2.81 & 0.023 & 0.487 & \\
\hline 169.747 & 0.0606 & 0.357 & 0.047 & 0.229 & \\
\hline 317.277 & 0.0606 & 0.191 & 1.65 & 0.229 & \\
\hline 244.354 & 0.0606 & 0.248 & 0.025 & 0.204 & \\
\hline 57.009 & 0.061 & 1.07 & 0.053 & 0.305 & \\
\hline 57.009 & 0.061 & 1.07 & 0.036 & 0.305 & \\
\hline 57.009 & 0.061 & 1.07 & 2.06 & 0.335 & \\
\hline 57.009 & 0.061 & 1.07 & 1.125 & 0.335 & \\
\hline 57.009 & 0.061 & 1.07 & 0.423 & 0.32 & \\
\hline
\end{tabular}




\begin{tabular}{|c|c|c|c|c|c|}
\hline 57.009 & 0.061 & 1.07 & 0.255 & 0.321 & \\
\hline 750 & 0.3 & 0.4 & & 0.326 & \\
\hline 272.727 & 0.3 & 1.1 & & 0.368 & Bai et al. (2005) \\
\hline 230.769 & 0.3 & 1.3 & & 0.398 & \\
\hline 2.075 & 0.083 & 40 & 0.108 & 1.2 & \multirow{24}{*}{ Yang et al. (2006) } \\
\hline 2.257 & 0.0903 & 40 & 0.648 & 1.44 & \\
\hline 3.49 & 0.1396 & 40 & 4.296 & 1.79 & \\
\hline 5.533 & 0.083 & 15 & & 0.964 & \\
\hline 4.667 & 0.035 & 7.5 & & 0.686 & \\
\hline 5.04 & 0.126 & 25 & & 1.19 & \\
\hline 5.075 & 0.203 & 40 & & 1.478 & \\
\hline 6 & 0.021 & 3.5 & & 0.571 & \\
\hline 6 & 0.009 & 1.5 & & 0.333 & \\
\hline 2.225 & 0.089 & 40 & & 1.348 & \\
\hline 2.56 & 0.064 & 25 & & 1.094 & \\
\hline 3 & 0.021 & 7 & & 0.714 & \\
\hline 2.667 & 0.04 & 15 & & 0.875 & \\
\hline 2.857 & 0.01 & 3.5 & & 0.4 & \\
\hline 7.2 & 0.054 & 7.5 & & 0.556 & \\
\hline 7.714 & 0.027 & 3.5 & & 0.444 & \\
\hline 10 & 0.015 & 1.5 & & 0.333 & \\
\hline 7.333 & 0.11 & 15 & & 0.864 & \\
\hline 8.16 & 0.204 & 25 & & 1.201 & \\
\hline 3.067 & 0.023 & 7.5 & & 0.565 & \\
\hline 3.428 & 0.012 & 3.5 & & 0.417 & \\
\hline 2.867 & 0.043 & 15 & & 0.814 & \\
\hline 3.28 & 0.082 & 25 & & 1.159 & \\
\hline 2.975 & 0.119 & 40 & & 1.345 & \\
\hline
\end{tabular}

